\title{
Development of a Calculation Basis for the Goals and Objectives of Innovation Management at Industrial Enterprises in the Context of Post-Conflict Transformation
}

\author{
Yuliia Klius*1, Yevhen Ivchenko ${ }^{2}$, Alexander Rozmyslov ${ }^{3}$, Vilen Fatalov ${ }^{4}$
}

\begin{abstract}
Innovation management objectives completion phases at the industrial enterprise were developed. At the first phase a hierarchy of the corporate goals is formed. It is based on the expert and creative decision-making methods for the areas of the company's activity (production area, managerial - human resource management, financial, marketing, information-technological) and management levels (strategic, tactical, operational). The expert assessments in the second phase identify the initial goals of the innovation management system. In the third phase the relationship between goals and existing innovations in the corporation are defined. At this stage, a system of innovation management goals is formed. The proposed structure and method for forming an innovation corporate base consisting of two modules (the individual and group innovation bases), the basis of which consists of a set of job assignments and corresponding to each job assignment a combination of individual and group innovations or knowledge about them. Each task corresponds to a specific goal of managing innovation. The economic impact of introducing an integrative approach to innovation management in industrial enterprises is calculated.
\end{abstract}

Keywords: mathematical basis, innovation activity, industrial enterprise, post-conflict transformation, approach, assessment, indicators.

\section{Introduction.}

The analysis of existing approaches to innovation management showed that in each approach the innovation, knowledge about innovation and related processes are treated as groups of distinct formalised parameters. The innovation management system itself is considered as a practically independent system that is not bound by a common goal with the company. This approach leads to technocratic and efficient consideration of innovation management processes. We have developed a mathematical approach to managing innovations in an enterprise in a post-conflict transition, based on the premise that an enterprise's goals should define the goals of managing innovation, while enterprise

\footnotetext{
${ }^{1}$ Doctor of Economic Sciences, Head of Department of Accounting and Taxation, Volodymyr Dahl East Ukrainian National University, Ukraine. *Corresponding Author.

${ }^{2}$ Doctor of Economic Sciences, Professor of Department of public administration, management and marketing, Volodymyr Dahl East Ukrainian National University, Ukraine.

${ }^{3} \mathrm{PhD}$ in Economic, Associate Professor, Department of Accounting and Taxation, Volodymyr Dahl East Ukrainian National University, Ukraine.

${ }^{4}$ Postgraduate, Volodymyr Dahl East Ukrainian National University, Ukraine.
} 
innovation management processes should be integrated with vertical and horizontal levels of business processes in post-conflict transformation.

The goals of innovation management are determined by the organizational goals of microlevel entities, one of the important tasks is the task of forming the goals of the organization. The enterprise's objective is the expected outcome or some future predetermined state of an object (enterprise itself, its performance indicators, business direction, functional block, production complex). The objectives of the company create an objectives tree. The objectives tree is viewed as a hierarchical, structured, level-distributed and ordered set of goals of the economic system, program, plan that defines: the general goal is the "root node"; the subordinate to it sub-goals of the first level "first level nodes"; subordinate to it sub-goals of the second level - "second level nodes"; etc.

The basis for building the root node and the first-level nodes are many strategic goals defined within the enterprise strategy. It is necessary to clarify that strategically important should be considered not only goals that determine the directions of strategic development, but also long-term goals associated with the support of the management system, but also with the production and provision of the company. Achieving strategic objectives is inextricably linked to the implementation of both tactical and operational objectives. The identification, definition and hierarchy ordering of each of the objectives is carried out through a series of analytical operations as well as harmonization and approval processes, as the goal of the innovation management is linked to the goals of the organization. Their content will depend on how the objectives of the organization are shaped.

\section{Development of a methodological approach to setting innovation management goals in industrial enterprises}

The proprietary research methodology considers the mathematical basis t0 innovation management in the methodological approaches system (transfer management, algorithmic management, creative management), based on the identified processes of innovation management at industrial enterprises in the context of post-conflict transformation.

Transfer management aims at managing various forms of innovation transfer and learning new innovations. Accordingly, transfer management is based on the transfer process and is aimed at managing various forms of innovations transfer between business partners and an industrial enterprise, external professional communities and an organization, between professional communities within an organization, internal professional communities, at employees' trainings [18].

Algorithmic control is designed to control cognitive processes that are, respectively, algorithmic in nature. It is based on the processes of finding sources of innovation, finding the innovations themselves, finding employees with the right innovations, identifying innovations in employees.

Creative management is the management of informal processes, which include the creation and improvement of innovations.

Accordingly, we analyse the approaches to establishing innovation management objectives in industrial enterprises in post-conflict transformation and justify our own approach. 
Objectives are a defined state of the specific desirable characteristics of the organization towards which its activities are directed. Objectives setting is the process of transforming a business's destination into some specific vector of goals. It should be noted that, in parallel with the objectives setting, the process of directing the action of each element of the organization into a single vector begins. Targets must be set for each outcome, and the manager at any level considers its importance to achieve success. The intermediate outcomes can be quite different, such as: increased dividends, return of investment, improved reputation of the company, confidence in the product quality or in scientific and technological leadership, ability to work in a post-conflict situation, to compete in the market, financial stability, diversification and so on

Setting objectives, increasing the level of specificity helps to move from a general, vague formulation of the enterprise's mission to a practical work plan with which success could be achieved. A specified objective includes a list of clear outcomes, the achievement of which requires some effort and organized action. The desire to move from changing the situation to the desired one makes the managers of the enterprise to be more creative, to improve their business reputation and financial characteristics, which, accordingly, requires the concentration of all the efforts and capabilities of the organization. Difficult but achievable objectives avoid self-deception by already achieved successes, hesitation, intrafirm confusion and ensure a balanced work of the enterprise.

Objectives are the formal expression of the expectations of owners and other stakeholders in a successful organization, e.g. employees, buyers, suppliers, etc. The objectives of an enterprise may be formulated by a shareholders' meeting, board members or the president (CEO) of the company.

The objectives of the organization may be:

to introduce a new product or service;

to enter the markets of the neighbouring regions;

to find other, cheaper sources of raw materials and energy without compromising the quality;

to obtain a return on the used capital of not less than 30 per cent (before interest and taxes are deducted);

to increase profit growth in proportion to sales growth.

The objectives are the starting point of planning; the objectives are the basis of organizational relationships; the objectives are the basis of the motivations used in the enterprise; the objective is the starting point in the process of monitoring and evaluating the performance of individual employees, entities and the organization as a whole. To the extent possible, each of the objectives is a subject to the requirements of specificity, measurability, achievability, realism, limited time, motivation.

Management value of the objectives - is an indispensable prerequisite, for its achievement, the objective must be defined in qualitative and quantitative indicators, the means of measurement of which must be recorded, and must contain the necessary minimum (maximum) values to be achieved.

Achievability and realism are important characteristics of the goal. Unattainable, unrealistic goals do not motivate the actors. Easily achievable targets are poorly motivated.

Attempts by a technologically weak enterprise to produce at world standards can result in the resignation of talented and sensible engineers and managers. The objectives should be 
specific, that is, understandable to the actor and unambiguously formulated. Those expected to do so must know what is expected of them. On the one hand, the objective should be described in as many qualitative terms as possible (better, more efficient, more flexible) and, on the other hand, should be quantified. The objectives of the enterprise should be measurable.

Industrial enterprises that set their objectives for the intermediate outcomes and then take active action to achieve them are more competitive than companies where managers operate on fuzzy, blurred, declarative goals. In the development of the objective, it is necessary to eliminate such wording as "maximise profit", "reduce expenses", "increase sales".

Such goals are immeasurable and the actor will not be able to measure progress towards them.

The objective should have a deadline. If there is no deadline, the actor will always return to the action starting point. For the actors to know the sequence of actions, stages, steps the time frame must be defined. The objective should include motivating staff in the right direction. It should be formulated clearly and formalized so that its impact on the staff is enhanced and its enforceability enhanced. Note that the oral objectives setting the may be forgotten. The objective has to be documented, with the deadlines, quantitative and qualitative indicators, to enable staff to be much more accurate in their performance. In order to avoid conflicts between individuals and units, the objective of an enterprise must be compatible with the goals of individuals and groups. The unacceptability of the objective by the staff results in its non-implementation, passivity. Hence, the formulation of the objective is a very important process that requires considerable effort to agree on common points of view and to negotiate.

Clarification of the strategic and political objectives of the enterprise is carried out through the formulation of its goals, coordination of additional operational sub-goals and tasks. This process is integral as it links corporate planning and business operations. Each department, as well as each team and employee, should have their own goals.

If the objective setting process is organized correctly, it goes through four phases:

detection and analysis of the environmental trends;

formation of goals for the organization as a whole;

development of the objectives hierarchy;

personal goals creation.

Let us consider these phases. Phase One. Environmental trends influence industrial objectives setting here. The objectives are flexible, but this does not mean that they should be tied to the environment only by adapting them to changes. Objectives should be based on consideration of the environment and set accordingly. It is therefore very important to identify trends that determine economic, social, political, scientific and technological developments in industrial enterprises in a post-conflict situation.

Phase Two. It is important to select from a wide range of possible characteristics of an enterprise's activities those for which the objectives of the enterprise are defined. For each purpose, a tool for quantifying its parameters is selected. The system of criteria based on which the objectives of an enterprise are determined is clearly relevant. Generally, the criteria are set by the organization's mission and by the outcomes of the analysis of the macro-environment, industries, competitors and other environmental features. It is 
necessary to take into account, which objectives were in progress in the previous stage and how their achievement contributed to the fulfilment of the enterprise's mission. The decision on the objectives of the enterprise depends on the resources available to the enterprise.

Phase Three. The objectives hierarchy allows the objectives identification to be simulated for all levels of the enterprise. The hierarchy itself is based on both long-term objectives and short-term objectives. The decomposition of the upper-level objectives on the lowerlevel objectives, as well as the process of erecting lower-level objectives with the higherlevel objectives, is possible with the help of the object tree, in which, taking into account the subordination, the strict dependency "objection- means" is fixed. It identifies which objections in practice are the means to achieve other objections.

Phase Four. In order to find its logical finality and become a real tool in fulfilling the objectives of the enterprise, the objectives hierarchy within the enterprise is brought up to the level of an individual employee. In this case, each employee is included, through his $\backslash$ her personal objectives, in the process of achieving jointly the final objectives of the enterprise. All employees of the enterprise know what they will achieve, how the results of their work will affect the final results of the enterprise and the extent to which their work will contribute to its advancement.

Of course, bringing together the interests of all the actors of the organization in objectives setting is a difficult task. The organization's top management considers the objectives as high returns, high dividends, higher stock prices, and security for the invested capital.

Employees' objectives are high wages, interesting and safe work, conditions for growth and development, good social security, etc. Buyers assume that the enterprise provides them with a product at a suitable price, appropriate quality, with good service and guarantees. Society expects the organization to solve individual social problems in society. The task of the managers is to account and merge in the main objectives of the enterprise all divergent interests.

Peter Drucker said that an enterprise should not focus on a single goal, but should determine several of the most significant guidelines, since its activities are objectively very diverse [13].

\section{Innovation management objective settings at the industrial enterprise in post- conflict transformation}

The objectives of the enterprise can be considered within eight key spaces.

1. Market position, which means that the company determines its position in relation to competitors, forming its competitiveness indicators.

2. Innovations that define new ways of doing business, such as:

production and introduction of new products in the existing market and new markets creation;

use of new technologies;

application of new methods to organise production.

3. Productivity, for which objectives are defined at the level of the relationship between the performance of an enterprise and its productive resources. Of course, that enterprise 
is more productive that uses fewer economic resources to produce certain amount of products.

4. Resources to be assessed by the enterprise according to their current level and future needs.

5. Profitability is the ability of an enterprise to generate revenues in excess of its expenses necessary to generate income. Profit objectives tend to indicate its required quantitative level.

6. Management aspects are expressed in the quality level of management, in the personal achievements of managers. Goals related to the quality of management are not directly related to obtaining short-term profits, because short-term profits are often the result of entrepreneurial flair and talent, but in the long run, well considered management methods are essential for the development and success of the enterprise.

7. The human resources are considered from the point of view of fulfilling the job descriptions and work ethics. The objectives should effectively reflect the ways in which employees in the enterprise are motivated, and the enterprise should recognize its responsibility to its employees.

8. Social responsibility is about understanding the duty of business to contribute to the well-being of society. Making a profit creates the preconditions for the society aggregate product growth, which means a higher standard of living in the country. Business influences social life not only in the sense of increasing opportunities for material growth, but also, responding to generally accepted social values, provides society with quality goods and services, create a favorable environment, participates in solving acute social problems, etc. It is possible to divide goals into strategic and financial ones. The strategic objectives are to achieve higher growth rates than the industry average, increase the market share, improve the quality of products and services compared to competitors, achieve lower costs, and improve the reputation of the enterprise.

It is clear that the numerical values of the parameters to be achieved, or their timeframes, are practically impossible to set for strategic purposes. It is more appropriate here to discuss long-term planning for an indefinite period. At the same time, some strategic objectives (e.g., achieving an advantage over competitors) have to be pursued continuously.

If financial and strategic objectives are aimed at achieving key results, then they have the highest priority. Trajectory and point objectives can be identified. Trajectory objectives set the general direction of development, reflecting the most general (systemic) issues. Point objectives are formulated to achieve certain outcomes.

Trajectory and point objectives are interrelated with the concept of long-term and shortterm goals. Trajectory objectives are considered as long-term, and point as short-term ones.

The objectives of the enterprise also depend on the length of the period of its achievement. A more ambitious objective requires a longer period of its achievement. Conversely, a larger time interval is considered when a larger objective is set.

Internal business processes shape the value proposition to the client. The result of internal processes is a leading indicator of future improvements in the parameters of the client and financial components. 
The learning and development component describes how people, technology and the overall atmosphere of the enterprise contribute to the implementation of the strategy. Improved performance of this component is a leading indicator for the components of internal business processes, customer and financial. Active use of intangible assets in solving strategic tasks helps to improve the performance of internal business processes, which, in turn, ensures success for customers and shareholders.

The system of David Norton and Robert Kaplan reflects the interdependence of the components and is a chain of cause-and-effect relationships of the enterprise objectives. However, the system does not separate the goals of three levels of management (strategic, tactical, operational), while in any area of activity there are tasks of strategic, tactical, operational levels. For example, for financial activities, forecasting indicators such as ROI, "shareholder value", "revenue growth" is a strategic task, their calculation is a tactical task, and data collection for calculation is an operational task. Besides, information technology is a component of learning and development, while it is a necessary tool for every components. The rationalism of performing any type of activity, including financial, production, marketing, human resources management, largely depends on the skills and level of mastering information technologies.

Therefore, we have identified five groups of objectives for industrial enterprise in the postconflict transformation: financial, production, marketing, human resource management, information and technical support. Each group of objectives has strategic, tactical and operational levels. Because we strive to formulate a system of innovation management objectives (i.e. training needs assessment), this classification of enterprise objectives is the most productive. This classification of the goals of the enterprise is the most productive, since it divides the objectives by the main areas of the organization's activities and distinguishes them at the level of top, middle management and performers

Now let us consider how the innovation management objectives are described.

Innovation management objectives are formed on the basis of the organization's objectives and form a system of innovation management objectives.

The system of innovation management objectives is presented as a system

$$
<Ц_{\mathrm{yi}}>=<<Ц_{\mathrm{yi}}^{\phi}>,<Ц_{\mathrm{yi}}^{\Pi}>,<Ц_{\mathrm{yi}}^{\mathrm{M}}>,<Ц_{\mathrm{yi}}^{\mathrm{y \Pi}}>,<Ц_{\mathrm{yi}}^{\mathrm{i}}>>\text {. }
$$

Its subsystems are innovation management objectives in financing, production, marketing, human resources and IT.

Each innovation management goal subsystem in the industrial enterprise area, in turn, includes sub-systems of innovation management goals at the strategic, tactical, operational levels:

financing: $<Ц_{\mathrm{yI}}^{\phi}>=<<Ц_{\mathrm{yI}}^{\mathrm{c \phi}}>,<Ц_{\mathrm{yI}}^{\mathrm{T} \phi}>,<Ц_{\mathrm{yI}}^{\mathrm{o \phi}}>>$;

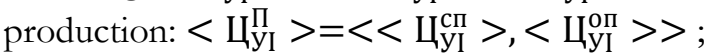

marketing: $\left.\left.<Ц_{\mathrm{YI}}^{\mathrm{M}}>=<<Ц_{\mathrm{YI}}^{\mathrm{CM}}\right\rangle,<Ц_{\mathrm{YI}}^{\mathrm{TM}}\right\rangle,<Ц_{\mathrm{yI}}^{\mathrm{OM}}>>$;

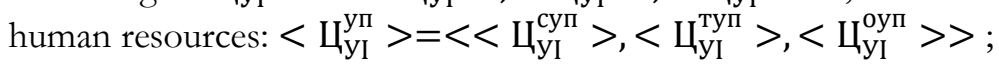

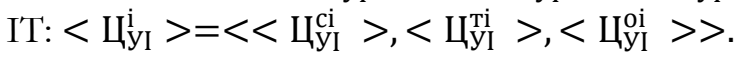

To implement the proprietary technology, it is proposed to use an algorithm that consists of three stages, implemented sequentially. At the first stage, a hierarchy of the corporation's objectives is formed based on expert and creative decision-making methods for the company's areas of activity (production, management, human resources, financial, 
marketing, information technology) and management levels (strategic, tactical, operational).

With the help of the expert assessments in the second stage, the initial objectives of the innovation management system are identified, which are necessary to achieve the objectives of the corporation for the above areas of activity and levels of management.

The third stage, based on the analysis of the identified in the second stage primary objectives of innovation management, is designed to define the relationship between the objectives and exist innovation in the corporation. At this stage, a system of innovation management objectives is formed.

Based on the above approaches to innovation management (transfer, algorithmic and creative) and the corresponding technologies, the innovation management objectives are achieved.

The received innovations are adapted to the peculiarities of the economic structure and are implemented. One of the outcomes of this process should be their accumulation in a single corporate innovation base.

The innovations corporate base means an intelligent information system that accumulates the outcomes obtained in the process of innovation management of the enterprise. The first of the technologies of innovation management is the transfer management technology. This is because in essence it is a reflection of transfer processes, which we consider to correspond to practical thinking.

Practical thinking within the professional activity framework is primarily aimed at the professional environment, so a practitioner will first of all look for the necessary innovations in it, establishing relationships with colleagues, business partners, learning, adopting experience.

In case of insufficiency of empirically found innovations, it logically transfer to a theoretical way of thinking and creating innovations.

The completion of the innovation management is its accumulation in the innovation base.

\section{A corporate innovation base formation at an industrial enterprise}

We propose a structure and technics to create a corporate innovation base, the basis of which is a set of job assignments and, corresponding to each job assignment, a set of individual and group innovations or knowledge about them. Each task corresponds to a specific objective of innovation management.

Job assignments, as well as individual and group innovations or knowledge about them, correspond to the levels of management (strategic, tactical and operational) and areas of the corporation.

Job assignments should be described on the basis of the following scheme: the first element is the place of this job assignment in the activity. The second element is the statement of the task, which consists of the formulation of the objectives for its implementation and output data. The third element is an indication of those regulated procedures that are required to complete the job assignment. A typical job assignment is a task that is generalized, typical for most professional situations. Obviously, professional activity consists of performing labor functions that require complex skills from a specialist, which require various innovations. But any typical task can be decomposed into a hierarchy 
of the subtasks, the low level of which consists of private subtasks. When forming job assignments, it is necessary to proceed from a typical job assignment, the implementation of which is preceded by training in solving particular problems. A private task is a task corresponding to an elementary professional situation. Tasks that can cover several elementary situations are defined as cross-cutting.

Job assignments that cover a large range of cross-cutting tasks are complex tasks. Complex tasks should cover the main content of a specialist's activity, provide possibility of transferring skills acquired in problem solving of one type to other types. For each job assignment, the formation of individual and group innovations is carried out, which are the results of transfer, algorithmic, creative innovation management.

The corporate innovation base includes two modules:

an individual innovation base (IIB) and a group innovation base (GIB).

An individual innovation base is a set of individual professionals' innovations used to solve problems in their area of activity.

Group innovation base is a set of group innovations used by members of the professional community or working group in their professional activities.

The model of individual innovation base can be described by merging W (multiple job assignments) and $\mathrm{X}^{\mathrm{i}}$ (multiple individual innovations):

$K^{\mathrm{i}}=W \cup X^{\mathrm{i}}$.

Multiple individual innovations on $\mathrm{i}$-job assignment we describe as $\mathrm{X}_{\mathrm{i}}^{\mathrm{I}}$. Then multiple $\mathrm{X}^{\mathrm{i}}$ individual innovations, formulated for all $\mathrm{n}$-job assignments, will be determined by as following:

$\mathrm{X}^{i}=\bigcup_{i=1}^{n} X_{1}^{I}$

Therefore, multiple individual professional innovations on $\mathrm{i}$-assignment $\mathrm{X}^{\mathrm{i}}$ we put as

$X_{\mathrm{I}}^{\mathrm{U}}=\mathrm{C}_{1}^{\mathrm{U}} \cup \mathrm{T}_{1}^{\mathrm{U}} \cup \mathrm{M}_{1}^{\mathrm{U}} \cup S_{1}^{\mathrm{U}} \cup N_{1}^{\mathrm{U}}$,

where $\mathrm{C}_{1}^{\mathrm{U}}$ - individual conceptual innovations;

$\mathrm{T}_{1}^{\mathrm{U}}$ - individual technological innovations;

$\mathrm{M}_{1}^{\mathrm{U}}$ - individual methodological innovations;

$S_{1}^{\text {U }}$ - individual situational innovations;

$N_{1}^{\mathrm{U}}$ - individual navigational innovation.

Thus, individual methodological and navigational innovations $\mathrm{M}_{1}^{\mathrm{U}}$ and $N_{1}^{\mathrm{U}}$ are expressed through individual methodological innovations by the stages of solving a job assignment (objective creation - $\mathrm{M}_{i}^{\mathrm{u} f}$, strategy - $\mathrm{M}_{j}^{\mathrm{uc}}$, tactics - $\mathrm{M}_{i}^{\mathrm{u} t}$, outcomes $-\mathrm{M}_{i}^{\mathrm{u} p}$, control- $\mathrm{M}_{i}^{\mathrm{u} k}$ ) and through the individual navigational innovations by the stages of the strategy $\left(N_{i}^{\mathrm{hC}}\right)$ and tactics $\left(N_{i}^{\text {Ut }}\right)$. 
Such a distribution of the innovations by the levels is connected with the definition of the innovations.

Methodological innovations - these are ways of solving a job assignment in a given organization, and they are considered at all levels of the problem solving.

Navigational innovations - these are examples of solving a job assignment, taken from the experience of other organizations and taking into account world scientific achievements In this regard, they are considered only in a generalized form at the strategic and tactical stages of the task.

These innovations are represented by the formulas:

$M_{i}^{\text {и }}=\mathrm{M}_{\mathrm{i}}^{\mathrm{uf}} \cup \mathrm{M}_{\mathrm{i}}^{\mathrm{hC}} \cup \mathrm{M}_{\mathrm{i}}^{\mathrm{ht}} \cup \mathrm{M}_{\mathrm{i}}^{\mathrm{up}} \cup \mathrm{M}_{\mathrm{i}}^{\mathrm{uk}}$

$N_{i}^{\mathrm{U}}=N_{\mathrm{i}}^{\mathrm{UC}} \cup N_{\mathrm{i}}^{\mathrm{ht}}$.

For a group innovation base, the model is built by analogy with the model of an individual innovation base, while the elements are not individual innovations, but group ones:

$$
K^{r}=W \cup X^{r}
$$

Multiple group innovations by the $i$-job assignment we will designate as $X_{i}^{r}$. Then multiple $X^{r}$ group innovations, formulated for all $\mathrm{n}$-job assignments, will be determined by the formula

$\mathrm{X}^{r}=\mathrm{U}_{i=1}^{n} X_{i}^{r}$.

Therefore, multiple $X_{i}^{r}$-group innovations by i-job assignment we will represent as the formula:

$X_{i}^{r}=\mathrm{C}_{i}^{r} \cup \mathrm{T}_{i}^{r} \cup \mathrm{M}_{i}^{r} \cup S_{i}^{r} \cup N_{i}^{r}$,

where $\mathrm{C}_{i}^{r}$ - group conceptual innovations;

$\mathrm{T}_{i}^{r}$ - group technological innovations;

$\mathrm{M}_{i}^{r}$ - group methodical innovations;

$S_{i}^{r}$ - group situational innovations;

$N_{i}^{r}$ - group navigational innovations;

Conceptual, technological, situational innovations are presented in the form of sets, the elements of which are separate inferences - innovation units.

Group, individual methodical innovations, which are a way to solve a problem, are written in the form of elements of innovations according to the stages of solving a job assignment: objective formation - $\mathrm{M}_{\mathrm{i}}^{r f}, \mathrm{M}_{\mathrm{i}}^{\mathrm{u} f}$;

strategy - $\mathrm{M}_{j}^{\Gamma \mathrm{C}}, \mathrm{M}_{j}^{\mathrm{uC}}$;

tactics $-\mathrm{M}_{i}^{r t}, \mathrm{M}_{i}^{\mathrm{u} t}$; 
outcomes $-\mathrm{M}_{i}^{\Gamma p}, \mathrm{M}_{i}^{\mathrm{u} p}$

control $\left.\mathrm{M}_{i}^{\Gamma k}\right), \mathrm{M}_{i}^{\mathrm{uk}}$.

$$
\begin{aligned}
& M_{i}^{\Gamma}=\mathrm{M}_{\mathrm{i}}^{\Gamma f} \cup \mathrm{M}_{\mathrm{i}}^{\Gamma \mathrm{C}} \cup \mathrm{M}_{\mathrm{i}}^{\Gamma t} \cup \mathrm{M}_{\mathrm{i}}^{\Gamma \mathrm{p}} \cup \mathrm{M}_{\mathrm{i}}^{\Gamma k} . \\
& M_{i}^{\mathrm{u}}=\mathrm{M}_{\mathrm{i}}^{\mathrm{u} f} \cup \mathrm{M}_{\mathrm{i}}^{\mathrm{CC}} \cup \mathrm{M}_{\mathrm{i}}^{\mathrm{ht}} \cup \mathrm{M}_{\mathrm{i}}^{\mathrm{up}} \cup \mathrm{M}_{\mathrm{i}}^{\mathrm{u} k} .
\end{aligned}
$$

Group and individual navigational innovations represent the other companies' positive experience in solving similar job assignments, so they are considered in two stages: strategy $\left(N_{i}^{\Gamma \mathrm{CC}} N_{i}^{\text {uc }}\right)$ and tactic $\left(N_{i}^{r t} N_{i}^{\text {ut }}\right)$ :

$$
N_{i}^{r}=N_{i}^{r c} \cup N_{i}^{r t}
$$

$N_{i}^{\text {и }}=N_{i}^{\text {uc }} \cup N_{i}^{\text {ut }}$

Consider methodological innovations in more detail. Many methodological group and individual innovations at the objective forming stage by the i- job assignment represent, respectively, a set of global goals:

$$
M_{i}^{r f}=\left\{y_{i l, \ldots,} y_{i m}\right\}, M_{i}^{\mathrm{u} f}=\left\{\mathrm{x}_{i l, \ldots,} \mathrm{x}_{i m}\right\}
$$

At the stage of strategy, many methodological group and individual innovations by the ijob assignment are multi global sub-problems:

$$
M_{i}^{\Gamma \mathrm{C}}=\left\{q_{i l}^{\Gamma}, \ldots, q_{i m}^{\Gamma}\right\}, M_{i}^{\text {uc }}=\left\{q_{i l}^{\text {u }}, \ldots, q_{i m}^{\text {u }}\right\},
$$

where $q_{i g}^{\Gamma}, q_{i g}^{\text {U }}$-global sub-problems, respectively, are formed by a group or individually, each global sub-problem is presented as a union of a set consisting of one global goal and a set of global initial data. Let us write down the global sub-problems formed by the group and the individual:

$$
\begin{aligned}
& q_{i g}^{\Gamma}=\left\{y_{i g}^{\Gamma}\right\} \cup\left\{X_{i g 1, \ldots,}^{\Gamma}, X_{i g r}^{\Gamma}\right\} ; \\
& q_{i g}^{u}=\left\{y_{i g}^{u}\right\} \cup\left\{X_{i g 1, \ldots,}^{u} X_{i g r}^{u}\right\},
\end{aligned}
$$

where $\left\{y_{i g}^{\Gamma}\right\}$ - a global goal, created by the group;

$\left\{X_{i g 1, \ldots,}^{\Gamma}, X_{i g r}^{\Gamma}\right\}$ - a global output generated by the group; 
$\left\{y_{i g}^{\Gamma}\right\}$ - a global goal created by the individual;

$\left\{X_{i g 1, \ldots,}^{\Gamma} X_{i g r}^{\Gamma}\right\}$ - a global output generated by the individual.

At the tactical stage, the solution of each global subtask is specified and for each subproblem there is a set of sub-problems of the $1^{\text {st }}, 2^{\text {nd }}$ and $3^{\text {rd }}$ levels for the methodological group innovations $\left\{q_{i l}^{\Gamma l}, \ldots, q_{i k 1}^{\Gamma l}\right\},\left\{q_{i l}^{\Gamma 2}, \ldots, q_{i k 2}^{\Gamma 2}\right\},\left\{q_{i l}^{\Gamma k}, \ldots, q_{i k_{k}}^{\Gamma k}\right\}$ and methodological individual innovations $\left\{q_{i l}^{\text {ul }}, \ldots, q_{i k 1}^{\text {ul }}\right\},\left\{q_{i l}^{\text {u2 }}, \ldots, q_{i k 2}^{\text {u2 }}\right\},\left\{q_{i l}^{\text {uk }}, \ldots, q_{i k_{k}}^{\text {uk }}\right\}$ :

$\mathrm{M}_{i l}^{r t}=\left\{q_{i l}^{\Gamma l}, \ldots, q_{i k 1}^{\Gamma l}\right\} \cup\left\{q_{i l}^{\Gamma 2}, \ldots, q_{i k 2}^{\Gamma 2}\right\} \cup \ldots \cup\left\{q_{i l}^{\Gamma k}, \ldots, q_{i k_{k}}^{\Gamma k}\right\}$

$M_{i}^{\text {ut }}=\left\{q_{i l}^{u l}, \ldots, q_{i k 1}^{\text {ul }}\right\} \cup\left\{q_{i l}^{u 2}, \ldots, q_{i k 2}^{u 2}\right\} \cup \ldots \cup\left\{q_{i l}^{u k}, \ldots, q_{i k_{k}}^{\text {uk }}\right\}$.

At the stage of obtaining outcomes, multiple methodological group and individual innovations for each job assignment will be written as:

$\mathrm{M}_{\mathrm{i}}^{\Gamma \mathrm{p}}=\left\{\mathrm{e}_{i l, \ldots,}^{\Gamma} \mathrm{e}_{i m}^{\Gamma}\right\} ;$

$\mathrm{M}_{\mathrm{i}}^{\mathrm{up}}=\left\{\mathrm{e}_{i l, \ldots,}^{\mathrm{u}} \mathrm{e}_{i m}^{\mathrm{u}}\right\}$,

where $\mathrm{e}_{i g}^{\Gamma}, \mathrm{e}_{i g}^{\mathrm{u}},-$ separate outcome.

A set of methodological group and individual innovations at the control stage is a set of conclusions on the correspondence of the obtained results to the desired:

$\mathrm{M}_{\mathrm{i}}^{\Gamma \mathrm{K}}=\left\{u_{i l, \ldots,}^{\Gamma} u_{i k}^{\Gamma}\right\}$

$\mathrm{M}_{\mathrm{i}}^{\mathrm{u \kappa}}=\left\{u_{i l, \ldots,}^{\mathrm{u}} u_{i k}^{\mathrm{u}}\right\}$.

Navigational innovations are presented at the strategy and tactics stages in a similar way, taking into account the fact that all formed elements are not the outcome of this organization's activity, but the other organizations' positive reference experience.

As a model for the corporate innovation base formation, we will consider a logical causeand-effect relationship, designated as " $\rightarrow$ ".

A feature of the causal relationship is that it shows the logic and order of the innovations formation. A general description of the cause-and-effect relationship, accumulates a knowledge unit, we write it as:

$S ; L ; A \rightarrow B ; C$,

where $\mathrm{S}$ - is description of a situation class in which a causal relationship can be used, in our case it is a job assignment $\left(W_{j}\right)$; 
$\mathrm{L}$ - is a condition, when the causal relationship is updated, that is the procedure for entering innovations into the innovation base by the innovation management manager $\left(P_{i}\right)$;

A - reason, or innovations obtained individually or in a group $\left(X_{i}\right)$;

$\mathrm{B}$ - consequence, or innovation accumulated in the innovation base $\left(R_{i}^{Z}\right)$;

$\mathrm{C}$ - an indication of the changes that need to be made to the elements of this causal relationship; in our case, this is a transition to the next knowledge (denoted as $i=i+1$ ) or to the next job assignment (denote as $j=j+1$ ).

Given the above, the causal relationship of the innovation base formation will be written as:

$\mathrm{W}_{\mathrm{j}} ; \mathrm{P}_{\mathrm{i}} ; \mathrm{X}_{\mathrm{i}} \rightarrow \mathrm{R}_{\mathrm{i}}^{\mathrm{X}} ; \mathrm{i}=\mathrm{i}+1$

to move to the next type of innovation;

$W_{j} ; P_{i} ; X_{i} \rightarrow R_{i}^{X} ; j=j+1$

to move to the next job assignment.

Consider the accumulation of innovations based on causation for a single job assignment. Since it is the same for group and individual innovations, we will not designate them specifically. The cause-and-effect relationship of the conceptual innovations accumulation $\mathrm{C}_{\mathrm{i}}$ by the $\mathrm{i}$-job assignments is presented as:

$\mathrm{W}_{\mathrm{j}} ; \mathrm{P}_{\mathrm{i}} ; \mathrm{C}_{\mathrm{i}} \rightarrow \mathrm{R}_{\mathrm{i}}^{\mathrm{c}} ; \mathrm{i}=\mathrm{i}+1$.

The causal relationship of the technological innovations accumulation $T_{i}$ by $i$-job assignment we will present as:

$\mathrm{W}_{\mathrm{j}} ; \mathrm{P}_{\mathrm{i}} ; \mathrm{T}_{\mathrm{i}} \rightarrow \mathrm{R}_{\mathrm{i}}^{\mathrm{T}} ; \mathrm{i}=\mathrm{i}+1$.

The causal relationship of the methodological innovations accumulation $M_{i}$ by the i-job assignment we will present as:

$\mathrm{W}_{\mathrm{j}} ; \mathrm{P}_{\mathrm{i}} ; \mathrm{M}_{\mathrm{i}} \rightarrow \mathrm{R}_{\mathrm{i}}^{\mathrm{M}} ; \mathrm{i}=\mathrm{i}+1$.

Taking into account the fact that methodological innovations are considered at the stages of solving a job assignment, the above presented causal relationship consists of included causal relationships.

The causal relationship of the methodological innovations accumulation at the goal-setting stage is presented in the form:

$\mathrm{W}_{\mathrm{j}} ; \mathrm{P}_{\mathrm{i}} ; M_{\mathrm{i}}^{\mathrm{f}} \rightarrow \mathrm{R}_{\mathrm{i}}^{\mathrm{fM}} ; \mathrm{i}=\mathrm{i}+1$.

The causal relationship of the methodological innovations accumulation at the strategic stage is presented in the form:

$\mathrm{W}_{\mathrm{j}} ; \mathrm{P}_{\mathrm{i}} ; M_{\mathrm{i}}^{\mathrm{c}} \rightarrow \mathrm{R}_{\mathrm{i}}^{\mathrm{cM}} ; \mathrm{i}=\mathrm{i}+1$.

The causal relationship of the methodological innovations accumulation at the tactical stage is presented in the form:

$\mathrm{W}_{\mathrm{j}} ; \mathrm{P}_{\mathrm{i}} ; M_{\mathrm{i}}^{\mathrm{t}} \rightarrow \mathrm{R}_{\mathrm{i}}^{\mathrm{tM}} ; \mathrm{i}=\mathrm{i}+1$.

The causal relationship of the methodological innovations accumulation at the outcome stage is presented in the form: 
$\mathrm{W}_{\mathrm{j}} ; \mathrm{P}_{\mathrm{i}} ; M_{\mathrm{i}}^{\mathrm{p}} \rightarrow \mathrm{R}_{\mathrm{i}}^{\mathrm{pM}} ; \mathrm{i}=\mathrm{i}+1$.

The causal relationship of the methodological innovations accumulation at the control stage is presented in the form:

$\mathrm{W}_{\mathrm{j}} ; \mathrm{P}_{\mathrm{i}} ; M_{\mathrm{i}}^{\mathrm{k}} \rightarrow \mathrm{R}_{\mathrm{i}}^{\mathrm{kM}} ; \mathrm{i}=\mathrm{i}+1$.

The causal relationship of the situational innovations $S_{i}$ accumulation by the i-job assignment we will present in the form:

$\mathrm{W}_{\mathrm{j}} ; \mathrm{P}_{\mathrm{i}} ; \mathrm{S}_{\mathrm{i}} \rightarrow \mathrm{R}_{\mathrm{i}}^{\mathrm{S}} ; \mathrm{i}=\mathrm{i}+1$.

The causal relationship of the accumulation of the reference innovations $H_{i}$ by the i-job assignment we will present in the form:

$\mathrm{W}_{\mathrm{j}} ; \mathrm{P}_{\mathrm{i}} ; \mathrm{H}_{\mathrm{i}} \rightarrow \mathrm{R}_{\mathrm{i}}^{\mathrm{H}} ; \mathrm{i}=\mathrm{i}+1$.

The causal relationship of the accumulation of the navigational innovations $N_{i}$ by the ijob assignment we will present in the form:

$\mathrm{W}_{\mathrm{j}} ; \mathrm{P}_{\mathrm{i}} ; \mathrm{N}_{\mathrm{i}} \rightarrow \mathrm{R}_{\mathrm{i}}^{\mathrm{N}} ; \mathrm{i}=\mathrm{i}+1$.

Taking into account the fact that navigational innovations are presented at the strategy and tactics stages for solving job assignment, there are such causal relationships.

The causal relationship of the accumulation of navigational innovations at the strategy stage is presented in the form:

$\mathrm{W}_{\mathrm{j}} ; \mathrm{P}_{\mathrm{i}} ; N_{\mathrm{i}}^{\mathrm{c}} \rightarrow \mathrm{R}_{\mathrm{i}}^{\mathrm{cN}} ; \mathrm{i}=\mathrm{i}+1$.

The causal relationship of the accumulation of navigational innovations at the tactics stage is presented in the form:

$\mathrm{W}_{\mathrm{j}} ; \mathrm{P}_{\mathrm{i}} ; N_{\mathrm{i}}^{\mathrm{t}} \rightarrow \mathrm{R}_{\mathrm{i}}^{\mathrm{tN}} ; \mathrm{i}=\mathrm{i}+1$.

A feature of the innovation base is that these innovations are also formed taking into account various forms of innovation presentation.

There are homogeneous and complex forms of innovation presentation.

The collection of forms can be described by the following expression:

$$
M_{1}=\{F, T, S, V, K, C\} \text {, }
$$

where $\mathrm{F}$ - formal presentation of innovations (F-form);

$\mathrm{T}$ - text presentation of innovations ( $\mathrm{T}$-form);

$\mathrm{S}$ - audio presentation of innovations (speech, sounds) form (S-form);

$\mathrm{V}$ - visual presentation of innovation ( $\mathrm{V}$-form);

$\mathrm{K}$ - kinestatic representation of innovations ( $\mathrm{K}$-form);

$\mathrm{C}$ - complex presentation of innovations (C-form).

With the help of the F-form, the content of formal laws, theorems, axioms is conveyed; through the T-form - the content of printed materials - articles, magazines, newspapers, books, patents, dissertations, reports, curricula, medical records of patients and other materials that do not contain mathematical expressions; using the S-form - the content of sound recordings, etc; using the V-form - the content of visual images; with the help of the $\mathrm{K}$-form - the content of actions, events. The C-form of presenting innovations combines several homogeneous forms at the same time, for example, text and auditory, kinestatic and visual, etc. The complex form of innovation presentation is widespread, 
combining auditory and visual forms and is called the audiovisual form - SV-form. With the help of this form, the content of television and film materials is expressed - television programs, films, newsreels, etc.

\section{Discussion of the innovation management economic outcome in the corporate structure}

To calculate the economic effect when using the innovation management system, it is necessary to proceed from the revenue growth assessment by increasing the total amount of innovation for all types of management.

To assess the economic effect of using an innovation management system in a corporation, the following formula is proposed:

$\boldsymbol{E}=\Delta \boldsymbol{B}^{\mathrm{i}}-\Delta 3^{\mathrm{i}}$,

(27)

where $\Delta B^{\mathrm{i}}$ - increase in the revenue due to increased innovation taken across all types of management;

$\Delta 3^{\mathrm{i}}$ - increase in the costs required for the corporate innovation management system implementation and operation.

The costs associated with the creation and operation of an innovation management system consist of the costs for the personnel managing innovations at industrial enterprises and the costs of creating, implementing and maintaining a corporate information system for managing innovation. Unfortunately, it is almost impossible to accurately estimate the revenue growth volume due to the increase in the total volume of innovations in an organization, therefore it is proposed to calculate this increase using the hierarchy method. The use of this method makes it possible, with a high degree of probability, to determine the revenue increase due to the factor influence of the innovation management system implementation at the industrial enterprises. These factors include: the exchange of innovations within the enterprise, as well as with the external environment, the search and discovery of innovative knowledge among employees, the innovations creation, the innovations accumulation.

The share of the increase in the company's revenue received from the use of the innovation management system, including the information system, is determined using coefficients that are calculated using the hierarchy analysis method. This method assumes a pairwise assessment of factors affecting the total change in the company's revenue.

The first level of hierarchies determines the procedure goals - the choice of the factor that most strongly affects the increase in revenue in the corresponding time interval.

The second level of the hierarchy determines the list of criteria for assessing factors depending on their influence (degree of impact) on the revenue growth.

It is proposed to use the following revenue growth scale as criteria:

1) minimal;

2) minor;

3) average;

4) significant; 
5) maximum.

The third level of the hierarchy include factors that also affect the growth of revenue, but are divided into two groups: cognitive factors and factors that are not directly related to the innovation management system. The description of all the factors influencing the revenue growth, but not related to the innovation management system, is not included in the scope of our study, therefore, in the future, we will call them non-cognitive factors and evaluate them together. Cognitive factors include:

1) availability of the innovation transfer management subsystem at the industrial enterprises (internal corporate innovations exchange and exchange of innovations with the external environment);

2) availability of the algorithmic innovation management at the industrial enterprises (search and detection of the employees' innovative knowledge);

3) availability of creative innovation management at the industrial enterprises (innovations creation);

4) availability of the innovations corporate base at industrial enterprises (accumulation of innovations).

These factors determine revenue growth using knowledge management systems. To compare the importance of the criteria, we define a scale of preference level from 1 to 5 , where 1 is equal importance, and 5 is a very strong advantage, and intermediate levels of preference can be described as: 2 - small, 3 - substantial, 4 - significant.

A matrix of pairwise comparisons is formed for all criteria. Then, for each criterion (minimum increase in revenue, insignificant, average, significant increase in revenue, maximum) matrices of pairwise comparisons of factors are formed. Moreover, the evaluation of the vector of priorities of the criterion is determined by the formula

$k^{m}=\sqrt[5]{\prod_{j=1}^{5} k_{m j}}$,

and for the normalized estimate of the criterion priority vector the formula is:

$$
k_{n}^{m}=\frac{\sqrt[5]{\prod_{j=1}^{5} k_{m j}}}{\sum_{i=1}^{5} \sqrt[5]{\prod_{j=1}^{5} k_{y}}}
$$

where $\mathrm{m}, \mathrm{n}$ - indexes, respectively, by rows and columns.

The formula for evaluating the criterion priority vector for the g-criterion has the form:

$$
g_{a^{1}}=\sqrt[5]{\prod_{j=1}^{5} g_{a_{I_{j}}}}
$$

and the formula for the normalized estimate of priority vectors for the $\mathrm{g}$ - criterion is: 
$g a_{n}^{m}=\frac{\sqrt[5]{\prod_{j=1}^{5} g_{a_{m}}}}{\sum_{i=1}^{5} \sqrt[5]{\prod_{j=1}^{5} g_{a_{j}}}}$

where $g$ - number of the criterion.

In the process of filling in each matrix (matrix of criteria or factors), the consistency of the matrix of pairwise comparisons is calculated.

Matrix consistency index is calculated by the formula:

$I=\frac{\alpha_{\max }-n}{n-1}$

where $\mathrm{n}-$ matrix dimension,

$\mathrm{n}=5, \alpha_{\text {max }}$ - maximum eigenvalue of a comparisons matrix.

Table 5.1 The matrix of the criteria pairwise comparison

\begin{tabular}{|c|c|c|c|c|c|c|c|}
\hline Criterion & 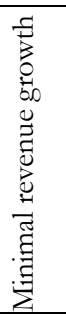 & 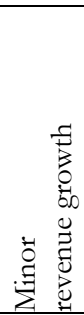 & 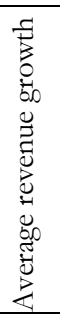 & 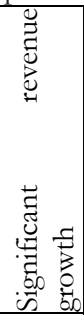 & 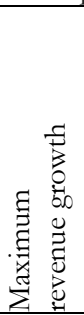 & $\begin{array}{l}\text { Criterion priority vector } \\
\text { estimation }\end{array}$ & $\begin{array}{l}\text { Normalized } \\
\text { estimation of the } \\
\text { criterion priority } \\
\text { vector }\end{array}$ \\
\hline $\begin{array}{l}\text { Minimal } \\
\text { revenue } \\
\text { growth }\end{array}$ & 1 & $k_{12}$ & $k_{13}$ & $k_{14}$ & $k_{15}$ & $k^{1}=\left(\prod_{j=1}^{5} k_{1_{j}}\right) 1 / 5$ & $k^{1}=\frac{\left(\Pi_{j=1}^{5} k_{1_{j}}\right)}{\sum_{i=1}^{5}\left(\Pi_{j=1}^{5} k_{i_{j}}\right)}{ }^{1 / 5}$ \\
\hline $\begin{array}{l}\text { Minor } \\
\text { revenue } \\
\text { growth }\end{array}$ & $k_{21}$ & 1 & $k_{23}$ & $k_{24}$ & $k_{25}$ & $k^{2}=\left(\prod_{j=1}^{5} k_{2_{j}}\right) 1 / 5$ & $k^{2}=\frac{\left(\Pi_{j=1}^{5} k_{2}\right)}{\sum_{i=1}^{5}\left(\Pi_{j=1}^{5} k_{i_{j}}\right)} 1 / 5$ \\
\hline $\begin{array}{l}\text { Average } \\
\text { revenue } \\
\text { growth }\end{array}$ & $\mathrm{k}_{31}$ & $k_{32}$ & 1 & $k_{34}$ & $k_{35}$ & $k^{3}=\left(\prod_{j=1}^{5} k_{3_{j}}\right) 1 / 5$ & $k^{3}=\frac{\left(\Pi_{j=1}^{5} k_{3}\right)}{\sum_{i=1}^{5}\left(\Pi_{j=1}^{5} k_{i_{j}}\right)}{ }^{1 / 5}$ \\
\hline $\begin{array}{l}\text { Significant } \\
\text { revenue } \\
\text { growth }\end{array}$ & $k_{41}$ & $k_{43}$ & $k_{43}$ & 1 & $k_{45}$ & $k^{4}=\left(\prod_{j=1}^{5} k_{4_{j}}\right) 1 / 5$ & $k^{4}=\frac{\left(\Pi_{j=1}^{5} k_{4}\right)}{\sum_{i=1}^{5}\left(\Pi_{j=1}^{5} k_{i_{j}}\right)} 1 / 5$ \\
\hline $\begin{array}{l}\text { Maximum } \\
\text { revenue } \\
\text { growth }\end{array}$ & $k_{51}$ & $k_{52}$ & $k_{53}$ & 1 & $k_{55}$ & $k^{5}=\left(\prod_{j=1}^{5} k_{5_{j}}\right) 1 / 5$ & $k^{5}=\frac{\left(\Pi_{j=1}^{5} k_{5}\right)}{\sum_{i=1}^{5}\left(\Pi_{j=1}^{5} k_{i_{j}}\right)} 1 / 5$ \\
\hline
\end{tabular}

Table 5.2 The matrix of the g-criterion factor pairwise comparison 


\begin{tabular}{|c|c|c|c|c|c|c|c|}
\hline Factor & 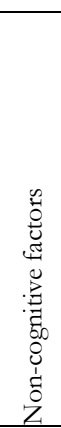 & 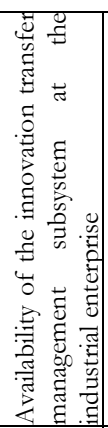 & 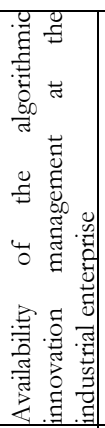 & 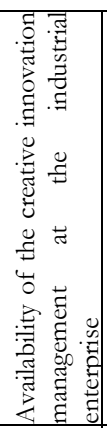 & 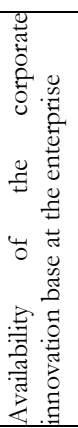 & $\begin{array}{l}\text { Criterion priority vector } \\
\text { estimation }\end{array}$ & $\begin{array}{l}\text { Normalized estimation } \\
\text { of the criterion priority } \\
\text { vector }\end{array}$ \\
\hline $\begin{array}{l}\text { Non- } \\
\text { cognitive } \\
\text { factors }\end{array}$ & 1 & $g_{a_{12}}$ & $g_{a_{13}}$ & $g_{a_{14}}$ & $g_{a_{15}}$ & $g_{a^{1}}=\left(\prod_{j=1}^{5} g_{a 1_{j}}\right) 1 / 5$ & $g_{a n^{1}=\frac{\left(\Pi_{j=1}^{5} g a_{1_{j}}\right)}{\sum_{i=1}^{5}\left(\Pi_{j=1}^{5} g a a_{j}\right)}}^{1 / 5}$ \\
\hline $\begin{array}{l}\text { Availability of } \\
\text { the } \\
\text { innovation } \\
\text { transfer } \\
\text { management } \\
\text { subsystem at } \\
\text { the industrial } \\
\text { enterprise }\end{array}$ & $g_{a_{21}}$ & 1 & $g_{a_{23}}$ & $g_{a_{24}}$ & $g_{a_{25}}$ & $g_{a^{2}}=\left(\prod_{j=1}^{5} g_{a 2_{j}}\right) 1 / 5$ & $g_{a n^{2}=\frac{\left(\Pi_{j=1}^{5} g a_{2_{j}}\right)}{\sum_{i=1}^{5}\left(\Pi_{j=1}^{5} g a 1_{j}\right)}}^{1 / 5}$ \\
\hline $\begin{array}{l}\text { Availability of } \\
\text { the } \\
\text { algorithmic } \\
\text { innovation } \\
\text { management } \\
\text { at the } \\
\text { industrial } \\
\text { enterprise }\end{array}$ & $g_{a_{31}}$ & $g_{a_{32}}$ & 1 & $g_{a_{34}}$ & $g_{a_{35}}$ & $g_{a^{3}}=\left(\prod_{j=1}^{5} g_{a 3_{j}}\right) 1 / 5$ & $g_{a n^{3}=\frac{\left(\Pi_{j=1}^{5} g a_{3_{j}}\right)}{\sum_{i=1}^{5}\left(\Pi_{j=1}^{5} g a 1_{j}\right)}} 1 / 5$ \\
\hline $\begin{array}{l}\text { Availability of } \\
\text { the creative } \\
\text { innovation } \\
\text { management } \\
\text { at the } \\
\text { enterprise }\end{array}$ & $g_{a_{41}}$ & $g_{a_{43}}$ & $g_{a_{43}}$ & 1 & $g_{a_{45}}$ & $g_{a^{4}}=\left(\prod_{j=1}^{5} g_{a 4_{j}}\right) 1 / 5$ & $g_{a n^{4}=\frac{\left(\Pi_{j=1}^{5} g a_{4_{j}}\right)}{\sum_{i=1}^{5}\left(\Pi_{j=1}^{5} g a_{1}\right)}} 1 / 5$ \\
\hline $\begin{array}{l}\text { Availability of } \\
\text { the corporate } \\
\text { innovation } \\
\text { base at the } \\
\text { enterprise }\end{array}$ & $g_{a_{51}}$ & $g_{a_{52}}$ & $g_{a_{53}}$ & 1 & $g_{a_{55}}$ & $g_{a^{5}}=\left(\prod_{j=1}^{\infty} g_{a 5_{j}}\right) 1 / 5$ & $g_{a n^{5}=\frac{\left(\Pi_{j=1}^{5} g a_{5_{j}}\right)}{\sum_{i=1}^{5}\left(\Pi_{j=1}^{5} g a 1_{j}\right)}}^{1 / 5}$ \\
\hline
\end{tabular}

Let us write the comparisons matrix maximum eigenvalue in general form for the matrix of factors by the g-criterion:

$\chi_{\max }=\mathrm{g}_{\mathrm{a}_{\mathrm{n}}^{1} \sum_{\mathrm{i}=1}^{5} \mathrm{~g}_{\mathrm{il}}+\cdots+\mathrm{g}_{\mathrm{n}}^{5} \sum_{\mathrm{i}=1}^{5} \mathrm{~g}_{\mathrm{i} 5}}$.

To ensure the admissibility of the obtained solution, the value of the consistency index must be more than 0.2 on the basis of the factors pairwise comparison matrices for the $g$ criterion, the global priorities on the following factors are defined by the following formulas:

for noncognitive factors: 


$$
\mathrm{B}_{1}=1_{\mathrm{a}_{\mathrm{n}}^{1}} \cdot \mathrm{k}_{\mathrm{n}}^{1}+\cdots+1_{\mathrm{a}_{\mathrm{n}}^{5}} \cdot \mathrm{k}_{\mathrm{n}}^{5}
$$

for the factor of the innovations transfer management subsystem availability:

$$
\mathrm{B}_{2}=2_{\mathrm{a}_{\mathrm{n}}^{1}} \cdot \mathrm{k}_{\mathrm{n}}^{1}+\cdots+2_{\mathrm{a}_{\mathrm{n}}^{5}} \cdot \mathrm{k}_{\mathrm{n}}^{5}
$$

for the factor of the innovations algorithmic management subsystem availability:

$$
\mathrm{B}_{3}=3_{\mathrm{a}_{\mathrm{n}}^{1}} \cdot \mathrm{k}_{\mathrm{n}}^{1}+\cdots+3_{\mathrm{a}_{\mathrm{n}}^{5}} \cdot \mathrm{k}_{\mathrm{n}}^{5}
$$

for the factor of the innovations creative management subsystem availability:

$$
\mathrm{B}_{4}=4_{\mathrm{an}_{\mathrm{n}}^{1}} \cdot \mathrm{k}_{\mathrm{n}}^{1}+\cdots+4_{\mathrm{a}_{\mathrm{n}}^{5}} \cdot \mathrm{k}_{\mathrm{n}}^{5}
$$

for the factor of the corporate innovation base availability:

$$
\mathrm{B}_{5}=5_{\mathrm{a}_{\mathrm{n}}^{1}} \cdot \mathrm{k}_{\mathrm{n}}^{1}+\cdots+5_{\mathrm{a}_{\mathrm{n}}^{5}} \cdot \mathrm{k}_{\mathrm{n}}^{5}
$$

Based on these factors, the share of revenue growth due to increased innovation is calculated $\Delta B^{\mathrm{U}}$ as a share of total sales growth $\Delta \mathrm{B}$ according to the formula:

$$
\Delta \mathrm{B}^{\mathrm{u}}=\Delta \mathrm{B} \cdot \sum_{i=2}^{5} B_{1}
$$

The effectiveness of the innovation management system at industrial enterprises should not only ensure an increase in financial indicators, but also the formation of additional company value. Its assessment is made using the indicator of economic value added, which can be determined by the formula:

$$
E V A^{\text {и }}=N O P A T^{\text {и }}-W A C C \cdot C A P I T A L^{\text {и }},
$$

where $N O P A T^{\text {и }}$-net operating profit less adjusted taxes, during the innovation management system implementation (Net Operating Profit Less Adjusted Tax);

WACC - Weighted Average Cost of Capital;

CAPIT A $L^{\text {и }}$ - capital invested to the innovation management system, UAH.

The results we have obtained are aimed at improving innovation management methods as a holistic mechanism in the context of transfer, algorithmic and creative approaches in order to accumulate and integrate innovations of corporations to improve the efficiency of their activities.

\section{Conclusion}

A model of an integrative approach to innovative management in corporate entities with a mathematical foundation has been developed. Our proprietary model of the innovative management is based on an integration approach. In modern corporate structures, innovation is divided into groups of independent properties. An innovation management system, if it exists, is considered as an independent system that has its own set of goals that are not integrated into the goals of the corporation itself. We consider the innovative management objectives in the integrated structure as the realization of the corporation goals, where the innovation management processes are horizontally and vertically integrated according to the business processes. In our opinion, the innovation management is based on three approaches: transfer, algorithmic and creative management. Transfer management is intended to manage and teach various forms of innovation 
transfer. Algorithmic management involves the management of innovative processes that are algorithmic in nature. These processes include the processes of finding new sources of innovation, including employees and external contractors who have the necessary innovations. Creative management, in turn, involves working with non-formalized or poorly formalized processes and includes the innovations creation and improvement.

To implement our proprietary methodology, it is proposed to use an algorithm that consists of three stages, which are implemented sequentially:

firstly, the corporate goals hierarchy formation, based on expert and creative decisionmaking methods in all areas of activity (production, marketing, finance, human resource management, information technology support) and management levels (strategic, tactical, operational);

secondly, identification of the innovation management initial objectives necessary for the implementation of the multiple corporate goals for the relevant areas of activity and levels of management;

third, identifying the relationship between the innovation management objectives, existing innovations and their sources, based on the above approaches to innovation management. The resulting innovations or knowledge about them are adapted to the objectives selected above and accumulated in the corporate database.

A system for evaluating the economic efficiency of innovation management in corporations is proposed. To calculate economic efficiency when using the innovation management system, it is necessary to assess the revenue growth by increasing the total amount of innovation for all types of corporate governance.

The practical significance of the results is that they can be applied in corporate integration structures to increase economic efficiency, making a profit from innovation.

\section{References:}

1. Butenko O. A. (2009), Formation of the state innovation policy. Investment: practice and experience, vol. 1 , pp. 21-24.

2. Zin E. The mechanism of development of regional innovation activity [Electronic resource - Access mode: http://www.ashsu.org/academy/herald_info/ visnyk_61_5_08 / visnyk_61_5_08_84-97.pdf

3. Zhihor O. B. (2009), Mechanism of realization of policy of innovative development of the region. Scientific Bulletin of NLTU of Ukraine. Issue 19.8. Pp. 133-139.

4. Polova N. M. (2009), Innovative directions of development of regional economy. Collection of scientific works of ChSTU. Series: Economic Sciences, Iss. 22, pp. 183-187.

5. Grinyova V. M., Vlasenko V. V. (2005), Organizational problems of innovative activity at the enterprise: monograph Kharkiv: INZHEK, 2005, 200 p.

6. Ilyashenko S. M. (2010), Innovative management: a textbook. Sums: University Book. 334 p.

7. Stadnik V. V, Yokhna M. A. (2006), Innovative management: a textbook. Kiev: Academic, 464 p.

8. Petukhova O. M. (2012), Formation of enterprise innovation management system. Science. Labor Nat. unfood. Technologies, № 43, P. 174-180.

9. Kozlovsky V. A. (2007), Innovative management: textbook. tool. Vinnytsia: VNTU, 210 p.

10. Mensch G. (1975), Das technoligishe Patt: Innovationen ubervinden die Depression. Frankfurt, 355 p

11. Freeman C. (1998), Structural Crises of Adjustment: Business Cycles and Investment Behavior. Technical Change and Economic Theory; [edited by Dosi G. Etal]. L.: Pinter Publishers, p. 38-66.

12. Cooper R. G. (2001), Winning at new products : Accelerating the process from idea to launch. Publisher: Basic Books. 416 p.

13. Drucker P. F. (1974), Management: Tasks, Responsibilities, Practicies. N. Y.: Harper L Rom, 218 p. 
14. Borghoff U., Pareschi R. (1998), Information Technology for Knowledge Management. Berlin: Springer Verlag. 56 p.

15. McElroy M. W. (2003), The new knowledge management: complexity, learning, and sustainable innovation. Butterworth-Heinemann.

16. Snowden D. (1998), The ecology of a sustainable Knowledge Management Program. Knowledge Management. № 1(6), p. 13-22.

17. Inkpen A., Dinur L. (1999), Knowledge Management Processes and International Joint Ventures. Organization Science, № 9(4), p. 454-468.

18. Klius Y. (2015), Corporate management system innovations: the formulation of this development. Lisichansk: Kit-L. 